\section{Comprehensive mineralogy}

Modern Mineralogy. By Keith Frye. Pp. ix +325. (Prentice-Hall: Englewood Cliffs, NJ, 1974.) £6.50.

MANY new mineralogy textbooks have appeared during the past decade; most have been devoted to specialised subjects and these have tended to replace the earlier type, which aimed at providing for the whole of a student's requirements up to the level of the first degree. With advance of knowledge and the need to explain quite sophisticated techniques even in an elementary book, it is no longer possible to provide a comprehensive text at an adequate level without making the volume unduly expensive, cumbersome and forbidding. Specialised books necessarily contain a much fuller treatment than the average student requires at an early stage but the rapid escalation in book prices has now reduced their attraction for purchase by students. To some extent this has restored the need for a new type of comprehensive text and this book is a valiant attempt to meet just this need. It is selective, it omits much of the conventional crystallographic introduction, and its stated purpose is to provide a sound physicallybased approach through familiar atomic theory and crystal structures in a logical sequence, and to introduce the student to present-day concepts of mineral formation and equilbrium. How well does it measure up to these rigorous requirements?

There are seven chapters and a 25 page tabular appendix of data on 150 common minerals. Chapter one is a fairly conventional crystal-chemical introduction that considers the nature of chemical bonds, close packing, ionic radii, simple model structures, defects and solid solution. It is pleasant to note the attention paid here to chemical and structural defects, to dislocations and to the evolution of grain boundaries. Chapter 2 provides a systematic account of the crystal structures found in minerals; again it follows a conventional treatment except where the model-structures theme is developed attractively by way of stuffed derivatives to explain many common rock-forming silicates. There follows in chapter 3 an all-embracing exposition of crystal symmetry, including lattices, point groups, the stereographic projection, crystal morphology, twinning and mineral habits, in 60 glorious pages. Logic seems to have quite deserted the author at this stage, for crystal structures have already been explained and many of the topics introduced (such as space groups) are certainly not needed for what follows. Chapters 4 and 5 are shorter; they are concerned with physical properties and the interaction of radiant energy with crystalline material. Topics dealt with here include mechanical behaviour, radioactivity, surface properties (but not pyro- and piezo-electricity) colour and lustre, atomic absorption, justification of the optical indicatrix, and the principles of X-ray diffraotion. Although this is attractively presented, as in chapter 3 it is difficult to understand why so many principles are explained, albeit brieffy, when no attempt is made to show how to use them. This middle part of the book is rather like Hamlet without the Prince of Denmark!

Chapter 6 is probably the best part of the entire book; it is excellent. Beginning with a concise and lucid explanation of the phase rule, it passes on to consider phase diagrams. It deals mostly with crystallisation and melting relations in binaries and ternaries, but regrettably does little on 3-phase triangles or on working out detailed courses of crystallisation. It then introduces isothermal and isobaric sections (used in the final chapter) and then passes on to a brief consideration of a quaternary system with a vapour phase. The final chapter spans an even vaster canvas-the whole of petrology! It begins with an enunciation of the principles of geochemistry and mineral formation and then proceeds to consider the classification and petrogenesis of igneous, sedimentary, and metamorphic rocks as well as some aspects of ore deposits. Although much of the treatment here is skilfully conceived as a consummation of all that has gone before, the familiar symptoms of extreme compression and a plethora of quite difficult new concepts, criticised earlier, here becomes a veritable disease. This must render the chapter virtually useless to an elementary student as a first reading. The repeated misuse of 'lattice' for 'structure' here is deprecated. I cannot see any value in the appendix, which is not sufficiently comprehensive to be of much use for identification yet takes up valuable space.

The diagrams are clear and well drawn but a few minor errors were noted (Fig. 6.13a). Separate author, mineral name and subject indexes are provided.

The author deserves full credit for producing an original, thoughtful and always interesting book which omits much of the irrelevant and otiose morphology still on offer in many. I do not wish to be pejorative but far too much has been attempted. the result being a book that is not really adequate as a crystallography, mineralogy or petrology text. It does not explain how to determine a point group, analyse a stereogram, use a polarising microscope or obtain information from an X-ray photograph. It does not explain the detailed reading of phase diagrams or how to describe a rock. Nevertheless it contains much information of value not easily found elsewhere and sections can be strongly recommended as further reading by more mature students and as a source of good ideas for elementary teaching. The author has demonstrated his ability to explain difficult ideas clearly, but the book would have fulfilled its rôle as a mineralogy text better if the final chapter and appendix had been omitted, the space saved being used to explain practical aspects of optics including some mention of reflected light, to expand the $\mathrm{X}$-ray section, and to say more on solid solution in rock-forming minerals.

\section{D. MUIR}

\section{Microscopy for all}

The Encyclopedia of Microscopy and Microtechnique. Edited by Peter Gray. Pp. xi+638. (Van Nostrand Reinhold: New York and London, January 1974.) $£ 16.25$.

IN recent years methods of microscopy and microtechnique have expanded at such a rapid rate that it is almost impossible to remain abreast of current developments in all but a small area of specialisation. This not only makes the provision of extensive reference books essential, it renders the task of their compilers almost impossible. The present book is, as the editor states in the preface, an attempt to cater for the needs of all who use the microscope, not only in the medical and biological sciences, but also among the "atmospherologists, bakers, chemists, metallurgists, textile workers, the manufacturers of paints and those who examine paintings". With such an implied wide-ranging coverage in mind, the need for interdisciplinary communication (especially with regard to such a basic tool as microscopy) is clearly apparent and the attempt is praiseworthy. In practical terms, however, it seems that it is not entirely successful. One wonders what the textile worker or paint manufacturer who uses the microscope will gain from the inclusion of a long description of the morphology and systematics of the annelids.

An attempt to cover the whole spectrum of possible microscope usage must fall far short in some fields and it seems that the basic fault of this book lies here. Had the coverage been limited to the instrument and to basic preparative techniques, the value of the book to all users of the microscope would have been increased and the topics could have been covered in more detail.

Most of the articles in this book (provided by about 180 specialists) are short, only one or two pages in length, 